Thorax (1976), 31, 245.

\title{
Bronchial adenoma: review of an 18-year experience at the Brompton Hospital
}

\author{
R. M. LA W S N, L R A M A N T H A N, G . HUR L E Y, \\ K. W. H I NSON, a nd S. C. LEN NOX
}

Brompton Hospital, Fulham Road, London SW3

\begin{abstract}
Lawson, R. M., Ramanathan, L., Hurley, G., Hinson, K. W., and Lennox, S. C. (1976). Thorax, 31, 245-253. Bronchial adenoma: review of an 18-year experience at the Brompton Hospital. Continued uncertainty about the prognosis for patients with bronchial adenomata led to a review of the experience of this condition in the Brompton Hospital. Of 72 patients seen between January 1955 and December 1972, 39 were women and 33 men, mean age 45 years, range 9-73 years. The commonest presenting symptoms were haemoptysis, cough, sputum, and repeated chest infections. Positive bronchoscopic biopsy occurred in 35 of 43 cases; five of these were originally reported as carcinomata, of oat-cell type in four. Plain chest film abnormality occurred in 69 patients. Seventy-three operative procedures comprised two endoscopic removals, two wedge resections, six bronchotomies, five pneumonectomies, and 58 lobectomies (seven with sleeve resection). Recurrence in three of six bronchotomies-two with adenoid cystic carcinomata (cylindromata)-necessitated further surgery. Lobectomy and lymph node dissection is usually the operation of choice. Histology confirmed 67 carcinoids (eight with atypical histology or lymph node metastases), two adenoid cystic carcinomata, one muco-epidermoid, and two mucous gland adenomata. Prolonged follow-up is especially indicated in patients with adenoid cystic carcinoma and in those with atypical or metastatic carcinoid histology. Although such pathology is not incompatible with long survival, of 10 patients in these categories, all five late deaths were probably related to the tumour. However, of 57 patients considered to have had typical carcinoid histology and adequate removal of the tumour, there has to date been no tumour-related death, but one patient developed radiosensitive atypical carcinoid tracheal tumours nine years later. The actuarially assessed survival of 71 patients undergoing surgery for bronchial adenomata was $75 \%$ at 15 years. Specific tumour types should replace the term bronchial adenoma.
\end{abstract}

When adding 22 cases of bronchial adenomata seen in the Brompton Hospital to the more than 100 cases previously documented, Foster-Carter (1941) stated that no death had ever been recorded from malignant change in a bronchial adenoma. Price-Thomas (1954), reporting a personal series of 41 bronchial adenomata treated in the Brompton and Westminster Hospitals, concluded that 'the incidence of malignancy is so low that it is possible for practical purposes to ignore it'. More recent papers have, however, questioned the use of the term bronchial adenoma, emphasizing not only the varying behaviour of the four tumour types included in the term-the bronchial carcinoid, the adenoid cystic carcinoma (cylindroma), the muco-epidermoid tumour, and the true bronchial mucous gland adenoma-but also the differing degrees of malignancy of the bronchial carcinoid itself (Donahue, Weichert, and Ochsner, 1968; Meffert and Lindskog, 1970; Tolis et al., 1972; Turnbull et al., 1972). In a Mayo Clinic series of 215 cases of bronchial carcinoid (Arrigoni, Woolner, and Bernatz, 1972), 23 (11\%) were considered to have atypical histological features and, of these, $70 \%$ metastasized and $30 \%$ were dead after a mean survival of 27 months. This is to be contrasted with the usual bronchial carcinoid five-year survival of $80 \%$ or more (Overholt, Bougas, and Morse, 1957; Donahue et al., 1967). 
Bronchial adenomata are uncommon tumours and no single surgeon can have a vast experience of their management. It was against this background of changing views on the benignity or otherwise of bronchial adenomata that we decided to update our experience of all such tumours seen at the Brompton Hospital between January 1955 and December 1972.

\section{HISTORICAL}

Mueller (1882) first described the carcinoid type of bronchial adenoma found at necropsy on a young woman who had suffered from haemoptysis and a chronic productive cough. From 1930 the term bronchial adenoma was used to differentiate this group of tumours, which differed in both morphology and behaviour, from the bronchogenic carcinoma (Kramer, 1930). In 1937 they were further subdivided into two histological subgroups, the carcinoids and the cylindromata (Hamperl, 1937). In 1952 Reid, noting the distinctive histology, the male predominance, the pronounced infiltrative tendencies, and a $25 \%$ incidence of distant metastases in patients with cylindromata, termed these tumours cystic adenoid carcinomata.

Hamperl believed that the bronchial carcinoid resembled the intestinal carcinoid, and his contention was challenged until Mattingly's association of the carcinoid syndrome with a bronchial carcinoid (Mattingly, 1956). The atypical carcinoid was first described in 1944 (Engelbreth-Holm, 1944) and the muco-epidermoid adenoma in 1945 (Smetana, Iverson, and Swan, 1952), and in 1956 a further variety, the cystadenoma or bronchial mucous gland adenoma, was added (Gilman, Klassen, and Scarpelli, 1956).

\section{MATERIAL AND METHODS}

The series includes all patients admitted to the Brompton Hospital between January 1955 and December 1972 in whom a diagnosis of bronchial adenoma was made on bronchial biopsy and/or on the resected lung specimen. The original histological findings in all 72 cases have been reviewed without the pathologist knowing the subsequent fate of the patient. The 72 plain chest radiographs, 28 tomograms, and nine bronchograms performed on these patients have also been re-examined.

A follow-up to July 1975 was then attempted on all 59 known survivors.

\section{RESULTS}

Clinical Material Among the 72 patients there was a slight predominance $(54 \%)$ of females. Al- though the age range of the series varied from $\frac{5}{9}$ to 73 years, $74 \%$ were between 30 and 60 (Fig. the mean age being 45 years.

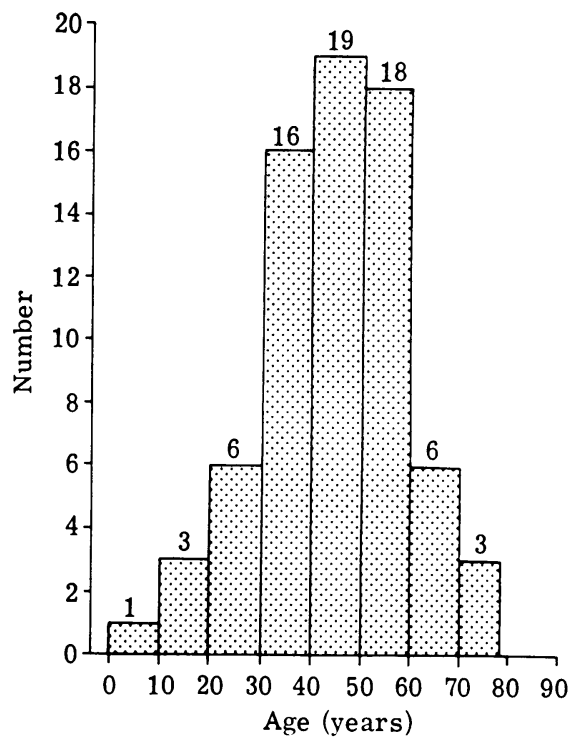

FIG. 1. Clinical material-age distribution.

SYMPTOMATOLOGY The symptomatology (Tabse I) is similar to that recorded in previous series. Haemoptysis had a considerable effect in haste ing the diagnosis of adenoma, the average duration of symptoms with haemoptysis being 17 mont (range 3 weeks- 8 years) and without haemoptysis 42 months (range 3 weeks -25 years). There was $\mathrm{n}$ case of carcinoid syndrome in the series.

T A B L E I SYMPTOMATOLOGY

\begin{tabular}{|c|c|c|}
\hline Symptom & No. & $\%$ \\
\hline $\begin{array}{l}\text { Haemoptysis } \\
\text { Persistent cough } \\
\text { Recurrent infection } \\
\text { Pain } \\
\text { Wheeze } \\
\text { Incidental x-ray }\end{array}$ & $\begin{array}{r}34 \\
26 \\
10 \\
9 \\
8 \\
13\end{array}$ & $\begin{array}{l}47 \\
36 \\
14 \\
12 \\
11 \\
18\end{array}$ \\
\hline
\end{tabular}

BRONCHOSCOPIC FINDINGS The bronchoscop: findings are shown in Table II. Bronchoscopy w艿 frequently omitted in patients with peripher 
T A B L E I I

BRONCHOSCOPIC FINDINGS

\begin{tabular}{|c|c|c|}
\hline $\begin{array}{l}\text { Number of patients } \\
\text { Bronchoscopy performed } \\
\text { Tumour visible }\end{array}$ & $\begin{array}{l}72 \\
60 \\
51\end{array}$ & \\
\hline Biopsy taken & 43 & $\begin{aligned} & 33 \text { Adenoma } \\
& 2 \text { Carcinoma } \\
& 8 \text { Infiammatory }\end{aligned}$ \\
\hline
\end{tabular}

tumours. An initial diagnosis of carcinoma (one reported as oat-cell and the other as 'probable carcinoma') was noted on bronchial biopsy in two patients. Subsequent examination of the operative specimens, however, revealed bronchial carcinoids in each. A further three patients were referred with alleged oat-cell carcinomata but a repeated bronchial biopsy and histological examination showed bronchial carcinoids in two and inflammatory changes' in the third. Examination of the subsequent operative specimens confirmed bronchial carcinoids in all three cases. Because of the possibility of bleeding, bronchial biopsy of the tumour was not always performed; on one occasion a swab of the tumour taken at bronchoscopy revealed carcinoid cells. However, no episode of severe bleeding followed biopsy in this series.

RADIOLOGICAL FINDINGS In 69 of the 72 cases an abnormality was noted on the plain chest radiograph (Table III). The common radiological presentation was of bronchial obstruction resulting in collapse and/or consolidation of a lung, lobe or segment. Fifty-three cases presented in this fashion and all were symptomatic. Compensatory emphysema was evident in the more severe cases of collapse. Three patients presented with obstructive emphysema due to incomplete obstruction by a ball-valve adenoma. A discrete, welldefined opacity was noted in 13 asymptomatic patients; these tumours arose from peripheral bronchi or as dumb-bell extrabronchial extensions

T A B L E I I I

RADIOLOGICAL FINDINGS ON PLAIN CHEST FILM

\begin{tabular}{l|c}
\hline Radiological Finding & No. \\
\hline Normal & 3 \\
Abnormal & 69 \\
Collapse/consolidation & 53 \\
With bronchicetasis & 25 \\
Discrete opacity & 13 \\
With calcification & 3 \\
Obstructive emphysema & 3 \\
\hline
\end{tabular}

from larger bronchi. In three patients no abnormality was seen on a plain chest radiograph, and in each a small non-obstructive tumour was seen in a main-stem bronchus at bronchoscopy; tomography subsequently demonstrated one of these tumours. Three adenomata showed radiographic evidence of calcification which was subsequently, in two, shown to be due to osseous metaplasia. In 25 patients, bronchiectasis had developed distal to a tumour, and in one patient two separate subpleural adenomata were found. Lytic osseous metastases occurred in two patients.

SURGICAL PROCEDURES The various procedures employed are illustrated in Figures 2, 3, and 4. Endoscopic removal was performed on a frail 70 year-old woman for a carcinoid tumour which

Bronchotomy

Bronchoscopic Removal 2

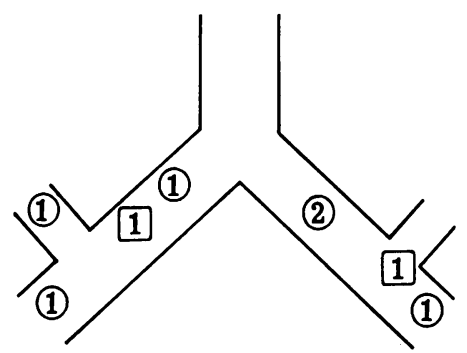

FIG. 2. Operative procedure-bronchoscopic removal and bronchotomy.

$\begin{array}{lr}\text { Pneumonectomy } & 5 \\ \text { Wedge Resection } & 2\end{array}$

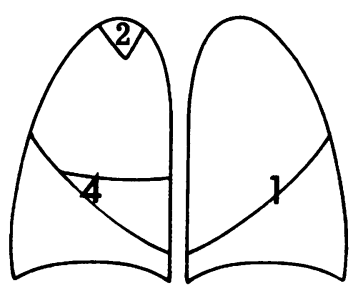

FIG. 3. Operative procedure-wedge resection and pneumonectomy. 


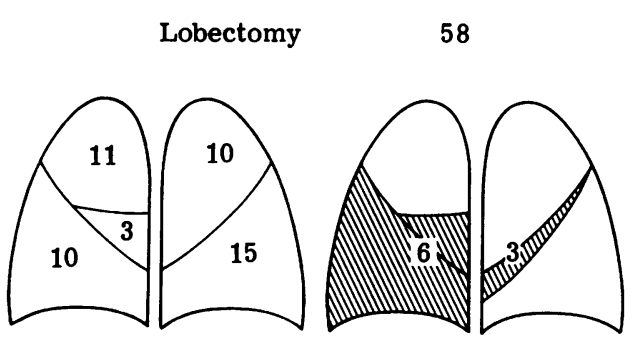

$\begin{array}{ll}\text { Sleeve Resection in (R) Upper Lobe } & 4 / 11 \\ \text { Sleeve Resection in (L) Upper Lobe } & 3 / 10\end{array}$

FIG. 4. Operative procedure-lobectomy.

would otherwise have necessitated a pneumonectomy. Temporary airway relief followed but there was a recurrence and she died eight months later. A second patient had a main-stem carcinoid tumour removed bronchoscopically and remains well 15 years later. Two of the six bronchotomies were performed on patients with main-stem cystic adenoid carcinoma and in both the tumour recurred ( 3 and 13 years later); each patient then required a pneumonectomy. The remaining four bronchotomies were performed for carcinoid tumours; two patients remain well 14 and 17 years later, and in a third the tumour recurred after five years, necessitating a lobectomy after which the patient remained well for a year and was then lost to follow-up. The fourth patient was also lost to follow-up after a main-stem bronchotomy.

The two patients who underwent wedge resection remain well four and 10 years later. Lobectomy or bilobectomy has been performed on 58 patients, in association with sleeve resection of the main-stem bronchus in seven of 21 upper lobectomies. The right lower lobe has been the commonest site of tumour origin. In five patients progressive inflammatory destruction of the lung necessitated a pneumonectomy.

MORTALITY AND MORBIDITY The single operative death in the series occurred in a 39-year-old woman proved at necropsy to have been due to pulmonary embolus. One patient required several bronchial dilatations after a lobectomy with sleeve resection, and another required closure of a bronchopleural fistula four months after a pneumonectomy. Both patients are well six and 11 years later. Another patient required a mainstem sleeve resection for a fibrous stricture occur- ring four months after a left upper lobectomy for? a carcinoid tumour. Nine years later he developed $\frac{0}{5}$ multiple tracheal tumours of an atypical carcinoid histological type. Although these responded welk to radiotherapy he now awaits investigation of a further stricture at the site of the previous sleeveresection. There is no evidence to date, however:that the stricture is due to further tumour.

SPECIMEN HISTOLOGY The series has been classi fied into the four tumour types present, and the $\omega$ carcinoid tumours have been further subdivided $\omega$ into histologically typical, atypical, and metastasizing types, that is, metastases occurring in lymph nodes in the operative specimen (Table IV).

\begin{tabular}{|c|c|c|}
\hline Histology & No. & \\
\hline $\begin{array}{l}\text { Carcinoid adenoma } \\
\text { Cystic adenoid carcinoma } \\
\text { Muco-epidermoid tumour } \\
\text { Adenoma of mucous glands }\end{array}$ & $\begin{array}{r}67 \\
2 \\
1 \\
2\end{array}$ & $\begin{array}{l}59 \text { Typical } \\
3 \text { Atypical } \\
5 \text { Metastasizing }\end{array}$ \\
\hline
\end{tabular}

Although the morphology of the typical carcinoid may vary from a highly differentiated structure consisting of tubules and glandular alveoli too sheets or clumps of cells, the cellular arrangement remains orderly with separation by stromal tissuej septae of varying vascularity and thickness. The cells are small and regular, mitotic figures areo rare, and capsular invasion does not occur (Fig. 5).

The atypical carcinoid is characterized by pleomorphism, nuclear irregularity with pro-․ㅡ․ minent nucleoli, hyperchromatism, increased mitotic activity, tumour necrosis, architecturaf disorganization, and capsular invasion (Fig. 6).

Of the five metastasizing carcinoids, two werew histologically atypical and three were typical.

ASSOCIATED LESIONS In one patient a carcinoide was associated with active tuberculosis, in another ${ }_{7}^{+}$ with a haemangioma, and in two others pulmonaryo ossification was noted. A further patient had as right upper lobe carcinoid treated with radon? seeds in 1934, reappeared with a destroyed right 0 upper lobe 27 years later, underwent right uppere lobectomy, and remains well a further 14 years later. Histological examination of the operative 


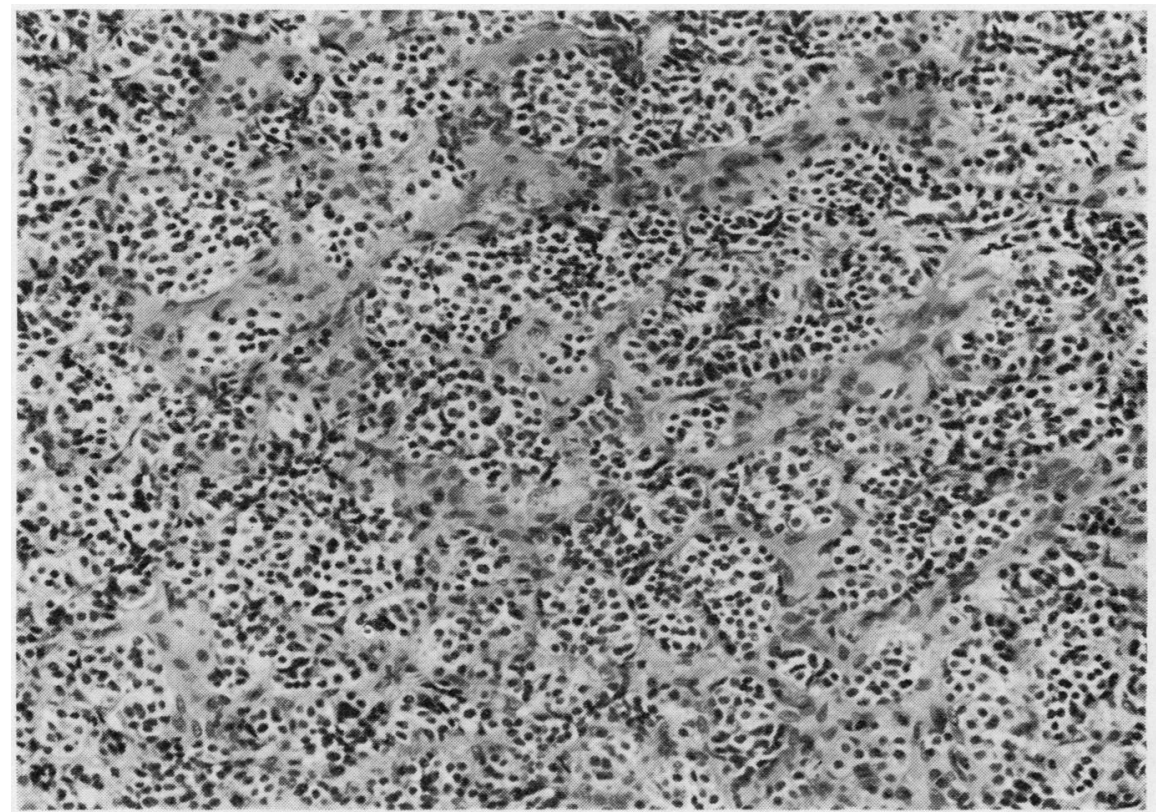

FIG. 5. Typical carcinoid histology. An orderly arrangement of regularly sized cells to form well-differentiated sheets and clumps of cells separated by stromal tissue septae is illustrated. A similar histological pattern was noted in all cuts of the tumour specimen (Haematoxylin and eosin $\times 118$ ).

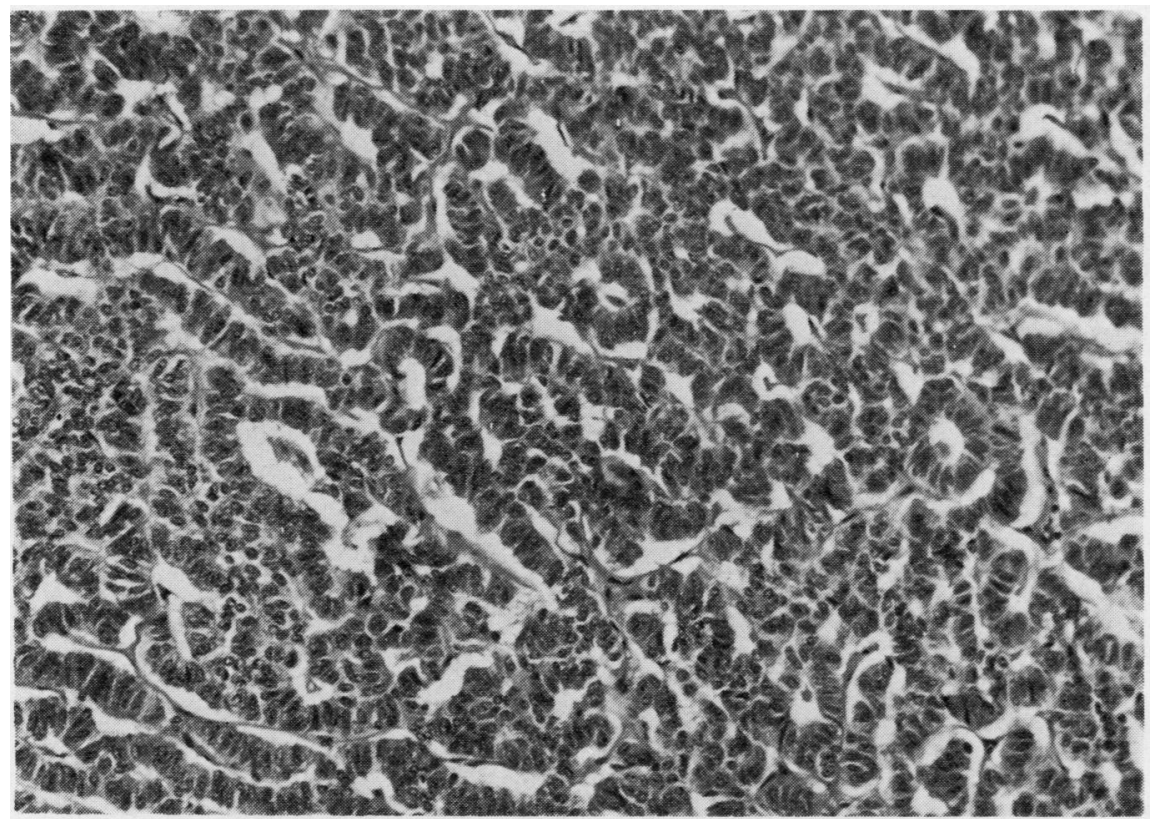

FIG. 6. Atypical carcinoid histology. The field illustrates many pleomorphic, hyperchromatic cells with increased mitotic figures. Typical carcinoid histology was noted in other fields from the same slide $(H$ and $E \times 118)$. 
specimen revealed recognizable carcinoid cells surrounded by calcium.

FOLLOW-UP Thirteen patients are known to have died, and of the 59 survivors, nine have been lost to follow-up within five years of surgery and a further seven have been followed up for at least five years and subsequently lost. The two patients with mucous gland adenomata remain well six years after resection. The single patient with a muco-epidermoid tumour died 10 years later of a cerebral haemorrhage. One of the patients with a cystic adenoid carcinoma died from metastases 16 years after initial bronchotomy and 13 years after a pneumonectomy for a recurrence; the other remains well 15 months after pneumonectomy for a main-stem recurrence 13 years after a bronchotomy.

Of the five metastasizing carcinoids, three are well at two, six, and eight years after operation, and two have died of multiple skeletal and visceral metastases at nine and 29 months. Two patients with atypical carcinoids died $7 \frac{1}{2}$ and $10 \frac{1}{2}$ years postoperatively; in one, multiple hepatic metastases were confirmed at necropsy and although necropsy was not performed in the other, clinical and radiological findings were suggestive of recurrent pulmonary tumour with cerebral metastases. The third patient with atypical carcinoid has recently presented 14 years later with histologically proven mediastinal carcinoid metastases.

Seven patients with typical carcinoid have since died, one in the early postoperative period of a pulmonary embolus and another eight months after partial endoscopic removal. A third died on admission, having refused surgery a year earlier; necropsy confirmed a lung abscess distal to a main-stem carcinoid. The remaining four deaths $(5,9,12$, and 16 years postoperatively) did not appear to be related in any way to the original histology.

Actuarially assessed survival of all 71 patients undergoing surgery indicates an 86\% 10-year and a 75\% 15-year postoperative survival (Fig. 7) (Anderson et al., 1974). The longest survivor in whom a bronchial carcinoid was diagnosed and treated by radon seeds in 1934, and who underwent a lobectomy in 1961, remains well 41 years later.

\section{DISCUSSION}

The sex distribution, average age, and symptomatology of this series of bronchial adenomata is

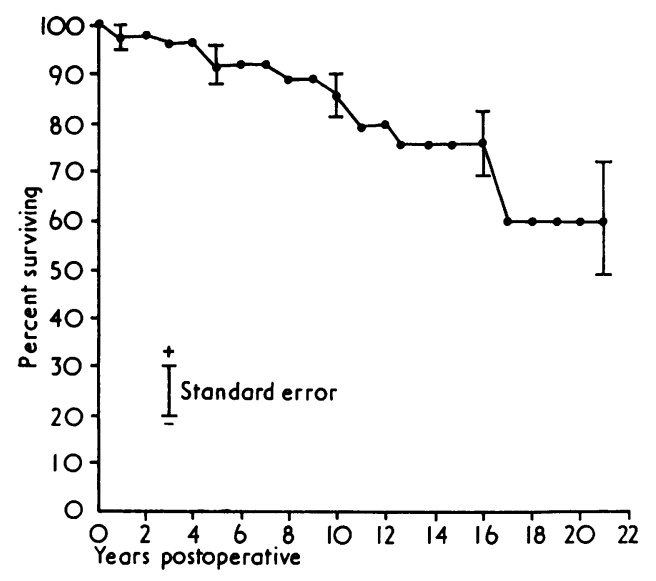

FIG. 7. Actuarially assessed survival following re moval of bronchial adenoma (71 patients). Plus of minus one standard error of the mean gives at approximate $67 \%$ confidence interval.

similar to those of others (Foster-Carter, $1941 \%$ Overholt et al., 1957; Weisel, Lepley, and Watsoro 1961; Zellos, 1962; Meffert and Lindskog, 1970). The duration of symptoms, however, even in the presence of haemoptysis, is still disturbingly long. The importance of early bronchoscopy for patients with unilateral wheeze, repeated chest infections non-productive cough, and haemoptysis (Prices Thomas, 1954) needs to be re-emphasized.

Difficulty in distinguishing between oat-ce carcinoma and bronchial carcinoid in a bronchia biopsy occurred on four occasions, three in patients referred as having oat-cell tumours? Similar diagnostic problems have been noted pre viously (Overholt et al., 1957; Zellos, 1962; Abbe Smith, 1969). Acceptance of the entity atypicaf carcinoid is unlikely to make this problem and easier and emphasizes the importance of caref 4 t histological examination of the whole of the excised operative specimen (Arrigoni et al., 197 by an experienced histopathologist. Althouge sputum cytology was negative in all patients if whom it was performed (as in almost every documented series), an accurate diagnosis of bronchiog carcinoid was achieved by bronchial swabbing of the one occasion it was tried. The diagnost accuracy of brush biopsy in bronchial adenoma 1 so far not established.

As in other series, the chest radiographs wer\& abnormal in almost all cases (Bower, 1965; Meffe 
and Lindskog, 1970). The usual siting of bronchial adenomata in main-stem and second- and thirdorder bronchi was reflected in the common radiological presentation of collapse and/or consolidation (McBurney, Clagett, and McDonald, 1952; Soutter, Sniffen, and Robbins, 1954). Although plain film evidence of bronchial obstruction is likely to be due to carcinoma, the appearance of obstruction in a younger patient, especially a female, with a long history of respiratory infections should suggest the diagnosis of bronchial adenoma. Evidence of bronchial dilatation, usually best shown by tomography, or an abrupt cut-off and absence of rat tailing on bronchography (Foster-Carter, 1941) proved helpful in suggesting the diagnosis in several patients. Tomography also proved useful in establishing the bronchus of origin of the tumour, a point of surgical importance. Pulmonary osseous metaplasia occurred in two patients (Price-Thomas and Morgan, 1958) and skeletal lytic metastases were noted in two others (Guistra and Stassa, 1969). Multiple bronchial adenomata, usually sited peripherally, are rare (Heimburger, Kilman, and Battersby, 1966); a further case occurred in this series. We agree with Zellos (1962) and Abbey Smith (1969) that lobectomy is usually the operation of choice, with sleeve resection of either main-stem bronchus if indicated. Contiguous lymph nodes should also be removed and examined for possible metastases. Pneumonectomy may be required if the lung has been destroyed distal to a main-stem adenoma. Bronchotomy is acceptable in main-stem lesions only if the tumour can be totally removed. Although long survival may follow bronchotomy performed on second-order bronchi, lobectomy offers a better chance of total removal of the tumour. Endoscopic removal should be reserved for unfit patients requiring relief of respiratory obstruction. Radon seed implantation produced temporary palliation in one patient with recurrent cystic adenoid carcinoma and in another with carcinoid, and radiation therapy has controlled atypical carcinoid tracheal tumours in a third patient.

Our series confirms the tendency for cystic adenoid carcinoma to recur and for mucous gland adenoma to remain benign. The possibility of late cystic adenoid carcinomatous recurrence necessitates prolonged follow-up and regular bronchoscopy in these patients. The single mucoepidermoid tumour in the series seemed benign, in contrast to the malignant type reported by Ozlu, Christopherson, and Allen (1961) and Turnbull et al. (1972). Follow-up of the bronchial carcinoid patients confirms the poorer prognosis for those with atypical histology or nodal metastases in the operative specimen. Of eight such patients, four died from nine months to $10 \frac{1}{2}$ years postoperatively, three with metastases proved at necropsy, and a fourth with clinical evidence of recurrence. Similar findings have been noted by Donahue et al. (1968) and Arrigoni et al. (1972), but Abbey Smith (1969) concluded that histopathology alone did not offer a reliable prognosis. The presence of lymph node metastases in the operative specimen, even of an atypical type, is compatible with prolonged survival, as illustrated by an eight-year survivor in our series. However, of 57 patients undergoing adequate excision of a typical carcinoid tumour, none of the four known late deaths was related to the tumour. One patient, with typical carcinoid in the original lobectomy specimen, developed multiple radiosensitive tracheal tumours nine years later, histology on this occasion revealing atypical carcinoid. Recurrence in a patient with typical carcinoid histology in the absence of lymph node involvement in the operative specimen has thus far been unique to this patient. The $86 \% 10$-year and $75 \% 15$-year actuarially assessed overall survival reflects the large number of patients with typical carcinoid histology in our series. A common cellular origin for oat-cell carcinoma and bronchial carcinoid has been suggested (Bensch et al., 1968); they may represent extremes of a spectrum of malignancy, the atypical and metastasizing carcinoids occupying an intermediate place. We would suggest the term carcinoid carcinoma for these intermediate types as being indicative of their metastatic potential. Because of the wide variation in malignancy of tumours hitherto termed bronchial adenomata (and the related prognosis for the patient) the collective term should now be abandoned and replaced by the specific tumour types.

We wish to thank Mr. N. R. Barrett, Lord Brock, Mr. W. P. Cleland, Mr. M. Paneth, and Mr. O. S. Tubbs for permission to include their patients in this series. We are indebted to $\mathrm{Mr}$. Grunkemeier for production of the life table and the actuarially assessed survival curve.

\section{REFERENCES}

Abbey Smith, R. (1969). Bronchial carcinoid tumours. Thorax, 24, 43.

Anderson, R. P., Bonchek, L. I., Grunkemeier, G. L., Lambert, L. E., and Starr, A. (1974). The analysis and presentation of surgical results by actuarial methods. Journal of Surgical Research, 16, 224. 
Arrigoni, M. G., Woolner, L. B., and Bernatz, P. E. (1972). Atypical carcinoid tumors of the lung. Journal of Thoracic and Cardiovascular Surgery, 64, 413 .

Bensch, K. G., Corrin, B., Pariente, R., and Spencer, H. (1968). Oat-cell carcinoma of the lung. Its origin and relationship to bronchial carcinoid. Cancer, 22, 1163.

Bower, G. (1965). Bronchial adenoma. A review of 28 cases. American Review of Respiratory Diseases, 92, 558 .

Donahue, J. K., Weichert, R. F., and Ochsner, J. L. (1968). Bronchial adenoma. Annals of Surgery, $167,873$.

Engelbreth-Holm, J. (1944). Benign bronchial adenomas. Acta Chirurgica Scandinavica, 90, 383.

Foster-Carter, A. (1941). Bronchial adenoma. Quarterly Journal of Medicine, 10, 139.

Gilman, R. A., Klassen, K. P., and Scarpelli, D. G. (1956). Mucous gland adenoma of bronchus; report of a case with histochemical study of secretion. American Journal of Clinical Patho$\log y, 26,151$.

Guistra, P. E. and Stassa, G. (1969). The multiple presentations of bronchial adenomas. Radiology, 93, 1013.

Hamperl, J. (1937). Über gutartige Bronchialtumoren (Cylindrome und Carcinoide). Virchows Archiv für pathologische Anatomie, 300, 46.

Heimburger, I., Kilman, J., and Battersby, J. (1966). Peripheral bronchial adenomas. Journal of Thoracic and Cardiovascular Surgery, 52, 542.

Kramer, R. (1930). Adenoma of bronchus. Annals of Otology, 39, 689.

Mattingly, T. W. (1956). Functioning carcinoid tumor -a new clinical entity. Review of the clinical features of the non-functioning and functioning carcinoid, including a review of 38 cases from the literature. Part II. Medical Annals of the District of Columbia, 25, 304.

McBurney, R. P., Clagett, O. T., and McDonald, J. R. (1952). Obstructive pneumonitis secondary to bronchial adenoma. Journal of Thoracic and Cardiovascular Surgery, 24, 411.

Meffert, W. G. and Lindskog, G. E. (1970). Bronchial adenoma. Journal of Thoracic and Cardiovascular Surgery, 59, 588.

Mueller, H. (1882). Zur Entstehungsgeschichte der Bronchialerweiterungen. Inaugural dissertation, Halle University. H. A. Busch, Ermsleben.
Overholt, R. H., Bougas, J. A., and Morse, D. BO (1957). Bronchial adenoma. American Review Tuberculosis and Pulmonary Diseases, 75, 865.

Ozlu, C., Christopherson, W. M., and Allen, J. एक Jr. (1961). Muco-epidermoid tumors of the bronchus. Journal of Thoracic and Cardiळ vascular Surgery, 42, 24.

Price-Thomas, C. (1954). Benign tumours of the lung Lancet, $1,1$. and Morgan, A. D. (1958). Ossifying bronchią adenoma. Thorax, 13, 286.

Reid, J. D. (1952). Adenoid cystic carcinoma (cylindroma) of the bronchial tree. Cancer, $\mathbf{5}$ 685.

Smetana, H. F., Iverson, L., and Swan, L. L. (1952 Bronchogenic carcinoma; an analysis of 108 autopsy cases. Military Surgeon, 111, 335.

Soutter, L., Sniffen, R., and Robbins, L. L. (1954). A clinical survey of adenomas of the trachea and bronchus in a general hospital. Journal के Thoracic Surgery, 28, 412.

Tolis, G. A., Fry, W. A., Head, L., and Shields, T. We (1972). Bronchial adenomas. Surgery, Gynecology and Obstetrics, 134, 605.

Turnbull, A. D., Huvos, A. G., Goodner, J. T., an Beattie, E. J. Jr. (1972). The malignant potentia of bronchial adenoma. Annals of Thorac Surgery, 14, 453.

Weisel, W., Lepley, D. Jr., and Watson, R. R. (1961胥 Respiratory tract adenomas. Annals of Surger 8 154, 898.

Zellos, S. (1962). Bronchial adenoma. Thorax, 12 61.

Requests for reprints to: R. M. Lawson, FRCS Brompton Hospital, Fulham Road, London SW3.

\section{ADDENDUM}

The table (opposite) illustrates the life table frong which the survival curve is derived. For details of the principles, methodology, and calculation of actuarial assessed survival see Anderson et al. (1974). ThE analysis and presentation of surgical results by actit arial methods. Journal of Surgical Research, 16, 22遭. 
A D D E N D U M T A L E LIFE TABLE

\begin{tabular}{|c|c|c|c|c|c|c|}
\hline $\begin{array}{c}\text { Years } \\
\text { Postop (K) }\end{array}$ & $\begin{array}{l}\text { No. of Patients } \\
\text { entering Interval } \\
\text { alive }\end{array}$ & $\begin{array}{l}\text { No. of Deaths } \\
\text { in Interval }\end{array}$ & $\begin{array}{l}\text { No. of Patients } \\
\text { surviving Interval } \\
\text { Incomplete }\end{array}$ & $\begin{array}{l}\text { No. lost to Follow- } \\
\text { up in Interval }\end{array}$ & $\begin{array}{c}\text { Survival Rate } \\
\operatorname{PK}_{\mathbf{K}}(\%)\end{array}$ & $\begin{array}{c}\text { Standard } \\
\text { Error of } \\
\mathbf{P}_{\mathbf{K}}(\%)\end{array}$ \\
\hline $\begin{array}{r}1 \\
2 \\
3 \\
4 \\
5 \\
6 \\
7 \\
8 \\
9 \\
10 \\
11 \\
12 \\
13 \\
14 \\
15 \\
16 \\
17 \\
18 \\
19 \\
20 \\
21\end{array}$ & $\begin{array}{r}71 \\
64 \\
62 \\
57 \\
52 \\
45 \\
42 \\
38 \\
33 \\
31 \\
26 \\
24 \\
21 \\
17 \\
16 \\
12 \\
10 \\
7 \\
3 \\
2 \\
2\end{array}$ & $\begin{array}{l}2 \\
0 \\
1 \\
0 \\
2 \\
0 \\
0 \\
0 \\
1 \\
0 \\
1 \\
2 \\
2 \\
0 \\
1 \\
0 \\
0 \\
0 \\
2 \\
0 \\
0 \\
0 \\
0 \\
0\end{array}$ & $\begin{array}{l}0 \\
1 \\
2 \\
4 \\
5 \\
3 \\
2 \\
3 \\
2 \\
1 \\
0 \\
3 \\
3 \\
1 \\
3 \\
2 \\
1 \\
4 \\
1 \\
0 \\
1\end{array}$ & $\begin{array}{l}5 \\
1 \\
2 \\
1 \\
0 \\
0 \\
2 \\
1 \\
0 \\
3 \\
0 \\
0 \\
0 \\
0 \\
1 \\
0 \\
0 \\
0 \\
0 \\
0 \\
0\end{array}$ & $\begin{array}{l}97 \\
97 \\
96 \\
96 \\
92 \\
92 \\
92 \\
89 \\
89 \\
86 \\
79 \\
79 \\
75 \\
75 \\
75 \\
75 \\
60 \\
60 \\
60 \\
60 \\
60\end{array}$ & $\begin{array}{r}2 \\
2 \\
3 \\
3 \\
4 \\
4 \\
4 \\
4 \\
4 \\
5 \\
7 \\
7 \\
7 \\
7 \\
7 \\
7 \\
12 \\
12 \\
12 \\
12 \\
12\end{array}$ \\
\hline
\end{tabular}

